\title{
The Varicella-Autoantibody Syndrome
}

\author{
CASSANDRA JOSEPHSON, RACHELLE NUSS, LINDA JACOBSON, MICHELE R. HACKER, \\ JAMES MURPHY, ADRIANA WEINBERG, AND MARILYN J. MANCO-JOHNSON \\ Departments of Pediatrics [C.J., R.N., L.J., M.R.H., A.W., M.J.M.-J.] and Preventive Medicine and \\ Biometrics [J.M.], University of Colorado Health Sciences Center, Denver, Colorado 80262, U.S.A., and \\ The Children's Hospital, Denver, Colorado 80218, U.S.A. [C.J., R.N., L.J., M.R.H., A.W., M.J.M.-J.]
}

\begin{abstract}
ABS
This cross-sectional study was conducted to determine the
incidence of autoantibodies to phospholipids and coagulation
proteins in children with acute varicella zoster virus (VZV)
infection. Study groups included children with VZV alone or
complicated by purpura fulminans and/or thromboembolism.
VZV naïve children and children who had VZV $>1$ y before
sample collection formed a control group. Blood was assayed for
the following: free protein $\mathrm{S}(\mathrm{PS})$, protein $\mathrm{C}$, antithrombin, and
prothrombin; antibody binding to these proteins; lupus anticoag-
ulant; anticardiolipin antibody; antiphospholipid antibodies; and
prothrombin fragment $1+2$. Data regarding coinfections was
collected. Forty-three VZV-infected children showed an in-
creased frequency of lupus anticoagulant, anticardiolipin anti-
body, antiphospholipid antibodies, and autoantibodies to PS,
protein C, prothrombin, and antithrombin in comparison to 52
children without acute VZV ( $p<0.0001)$. Seventeen children
with VZV and purpura fulminans and/or thromboembolism
showed a statistically significant decrease in free PS, signifi-
cantly increased PS IgG antibody, and significantly increased
prothrombin fragment $1+2$ ( $p<0.0001)$ compared with the
group without acute VZV and the group with uncomplicated
VZV. Twenty-six children with uncomplicated VZV showed
\end{abstract}
increased PS IgG antibody $(p<0.001)$ compared with the children without acute VZV. For all groups combined, elevated PS IgG antibody showed negative correlation with free PS $(p<$ $0.0001)$ and positive correlation with prothrombin fragment $1+2$ $(p=0.0002)$. Autoantibodies were transient. Transient antiphospholipid and coagulation protein autoantibodies were common with VZV infection, but were not predictive of thrombotic complications. (Pediatr Res 50: 345-352, 2001)
ACA, anticardiolipin antibody

\section{Abbreviations}
APA, antiphospholipid antibody
AT, antithrombin
F II, prothrombin, or factor II
F $\mathbf{1 + 2}$, prothrombin fragment $1+2$
GABHS, group A $\boldsymbol{\beta}$-hemolytic Streptococcus LA, lupus anticoagulant
$\mathbf{P C}$, protein $\mathrm{C}$
$\mathbf{P F}$, purpura fulminans
$\mathbf{P F} \pm \mathbf{T E}$, purpura fulminans and/or thromboembolism
PS, protein $\mathrm{S}$
VZV, varicella zoster virus

In a 1990 review, Francis (1) reported the association of VZV and/or streptococcal infection in $30 \%$ of children with idiopathic purpura fulminans. Subsequently, acquired free PS deficiency was described in children and adults with acute VZV infection and PF \pm TE (2-8). We reported the LA and free PS deficiency in seven previously healthy children with acute VZV infection complicated by PF \pm TE (6). We previously found evidence suggestive of an autoimmune cause of acquired PS deficiency.

We now report a cross-sectional study designed to determine the prevalence of autoantibodies directed against a variety of phospholipids and coagulation proteins in previously healthy

Received January 4, 2000; accepted February 26, 2001.

Correspondence and reprint requests: Marilyn J. Manco-Johnson, M.D., Mountain States Regional Hemophilia and Thrombosis Center, PO Box 6507, Mail Stop F416, Aurora, CO 80045-0507; e-mail: marilyn.manco-johnson@uchsc.edu

Supported by NIH grant M01 RR00069, from the General Clinical Research Centers Program, National Center for Research Resources. children with VZV infection. The aim of this study was to compare results obtained on blood samples from children with uncomplicated acute VZV infection with samples from children with acute VZV complicated by symptomatic PF \pm TE. It was hypothesized that coagulation abnormalities in the children with symptomatic PF \pm TE would be more prevalent and more severe but not intrinsically different from those found in healthy children with uncomplicated VZV infection.

\section{METHODS}

\section{Clinical Methods}

This cross-sectional study was performed with the approval of the Colorado Multi-Institutional Review Board and the Pediatric Clinical Research Center at The Children's Hospital of Denver. Informed consent and assent forms were signed before enrollment in the study. 
Three study groups of children were identified and recruited concurrently. Group 1 was composed of children who had no history of VZV infection or had VZV $>1$ y before sample collection, no personal or family history of bleeding or thrombotic disorders, and no evidence of infection or antibiotic use for at least $4 \mathrm{wk}$ before blood sampling. Group 2 included children with acute uncomplicated VZV infection and no personal or family history of bleeding or thrombotic disorders. Group 3 was composed of children with acute VZV infection complicated by $\mathrm{PF} \pm \mathrm{TE}$.

Children were recruited at Pediatric Resident Continuity Clinics at Denver Health Medical Center, The Children's Hospital of Denver, from staff members at The University of Colorado Health Sciences Center, or by referral to one of the authors. The diagnosis of VZV was made on visual inspection of typical skin lesions and confirmed with IgG serology. The diagnosis of purpura fulminans was made clinically and included typical palpable, indurated skin lesions of the trunk and extremities progressing from dark red to black and resulting in skin necrosis. All diagnoses of purpura fulminans were made in the pediatric intensive care unit of The Children's Hospital of Denver. All diagnoses of thromboembolism were confirmed with high-resolution real-time and Doppler ultrasonography, magnetic resonance angiography, or pulmonary ventilation/ perfusion scanning as appropriate. The diagnosis of Streptococcus was made on the basis of the result of clinically ordered blood or skin cultures.

Children between the ages of 3 mo and 18 y were eligible for the study. Nine milliliters of blood drawn into $1 \mathrm{~mL}$ of $3.8 \%$ sodium citrate and $5 \mathrm{~mL}$ of whole blood were collected from each subject. Citrated samples were immediately placed on ice and centrifuged twice at $1800 \times g$ for $20 \mathrm{~min}$ at $4^{\circ} \mathrm{C}$. Whole blood samples were allowed to clot at $37^{\circ} \mathrm{C}$ for $1 \mathrm{~h}$ before separating serum. Aliquots of plasma and serum were frozen at $-70^{\circ} \mathrm{C}$ until the time of assay.

Three children whose samples were included in group 1 subsequently developed VZV infection. They and their parents agreed to additional blood sampling at the time of acute uncomplicated VZV infection and 3 mo after VZV infection. Blood samples drawn at the time of acute uncomplicated VZV from these three children were included in group 2.

\section{Laboratory Methods}

Plasma concentration of the vitamin K-dependent anticoagulant PS was determined for the study groups. For comparison, F II was chosen as a vitamin K-dependent procoagulant protein, $\mathrm{PC}$ as a vitamin $\mathrm{K}$-dependent anticoagulant protein, and $\mathrm{AT}$ as a vitamin $\mathrm{K}$-independent anticoagulant protein. To determine whether there is an autoimmune basis for protein deficiencies, ELISA assays were performed to detect plasma IgG and IgM antibodies binding to PS, PC, F II, and AT. To determine whether an individual had a hypercoagulable state, plasma concentrations of the prothrombin activation fragment, F $1+2$, were assayed.

Purified antigens used to determine antibody specificity. Varicella antigens were purchased from BioWhittaker (Walkersville, MD, U.S.A.). PS, PC, AT, and F II were obtained from Enzyme Research (South Bend, IN, U.S.A.). Fibrinogen was purchased from Kabi Vitrum (Stockholm, Sweden).

Antibody to $\boldsymbol{V Z Z}$. An IgG antibody response to VZV was determined using an ELISA assay (VZV STAT, BioWhittaker).

Lupus anticoagulant. The LA was deemed present if there was prolongation of the activated partial thromboplastin time (APTT) or dilute Russell viper venom time that did not correct with the addition of 1:1 standard normal plasma and corrected with addition of platelet phospholipid in accordance with the criteria of the Lupus Anticoagulant Subcommittee of the International Society for Thrombosis and Haemostasis (9).

Anticardiolipin antibody. IgG and IgM antibodies to cardiolipin were determined in ELISA assays (Inova, San Diego, CA, U.S.A.) (10).

Antiphospholipid antibody. $\operatorname{IgG}$ and $\operatorname{IgM}$ antibodies in a mixture of cardiolipin, phosphatidic acid, and phosphatidylserine were semiquantitatively measured in an ELISA assay containing $\beta_{2}$-glycoprotein I (Asserachrom APA, American Bioproducts, Parsippany, NJ, U.S.A.). In this manuscript, APA will represent this specific ELISA test and not the more general term, antiphospholipid antibody.

Plasma concentrations of coagulation proteins. Free PS antigen concentrations were determined in an ELISA assay (Asserachrom Free Protein S, Diagnostic Stago, France). For this study we chose to assay free PS, or the compartment of PS not bound to circulating $\mathrm{C}_{4} \mathrm{~b}$-binding protein, because the free compartment of PS contributes anticoagulant function and because free PS deficiency was found to be most severe in the seven originally published patients with VZV-induced PS deficiency. PC activity was quantified in a chromogenic assay (Coamatic Protein C, Chromogenix, Milan, Italy). F II activity was determined in a standard one-stage clotting assay. AT activity was assessed in an amidolytic assay (Coamatic Antithrombin III, Chromogenix).

Prothrombin fragment 1+2. Plasma concentrations of the prothrombin activation fragment, F $1+2$, were determined using an ELISA assay (Ezygnost F 1+2, Behring Diagnostics Inc., Westwood, MA, U.S.A.).

Plasma concentrations of IgG and IgM antibodies to coagulation proteins. Binding of patient plasma IgG or IgM to coagulation proteins was determined in ELISA assays. One hundred microliters of purified capture antigen diluted in carbonate buffer was applied to a 96-well ELISA plate (Nunc Maxisorb substrate kit (contains peroxidase solution and 3, 3', 5, $5^{\prime}$ tetramethylbenzidine, Pierce Chemical Co., Rockford, IL, U.S.A.) and incubated for $2 \mathrm{~h}$ at $20^{\circ} \mathrm{C}$. The plates were washed three times after application of capture antigen using a PBS containing BSA and Tween 20. The plates were then blocked three times with Superblock (Pierce Chemical Co., Rockford, IL, U.S.A.). One hundred microliters of patient plasma, diluted 1:500-1:40,000 in Superblock plus $0.05 \%$ Tween 20, was applied and incubated for $2 \mathrm{~h}$ at $20^{\circ} \mathrm{C}$. After application of plasma, plates were again washed three times. One hundred microliters of horseradish peroxidase-conjugated goat antihuman IgG or IgM Fc-specific antibody was applied and incubated at room temperature for $1 \mathrm{~h}$. Finally, the sample was washed three times, and the color was developed with TMB, Nalge Nunc International, Rochester, NY, U.S.A. OD was 
Table 1. Clinical information for group 3 children

\begin{tabular}{|c|c|c|c|c|c|c|}
\hline Patient & Age (y) & Sex & Days* & Complications & Secondary infection & Outcome \\
\hline 1 & 0.5 & $\mathrm{M}$ & 23 & Myocardial infarct & GABHS sepsis & Died \\
\hline 2 & 0.6 & M & 6 & Purpura fulminans & GABHS sepsis & Survived, no sequelae \\
\hline 3 & 0.8 & $\mathrm{~F}$ & 4 & Purpura fulminans & GABHS cellulitis & Lost to follow-up \\
\hline 5 & 1.1 & $\mathrm{~F}$ & 28 & Middle cerebral artery thrombosis & & Lost to follow-up \\
\hline 6 & 2.0 & M & 21 & Middle cerebral artery thrombosis & & Spastic hemiplegia \\
\hline 7 & 3.0 & $\mathrm{~F}$ & 21 & Stroke & & Survived, no sequelae \\
\hline 10 & 5.0 & M & 49 & Central nervous system capsular emboli & & Survived, no sequelae \\
\hline 11 & 6.0 & $\mathrm{~F}$ & 16 & Purpura fulminans, pulmonary embolism & GABHS cellulitis & Survived, no sequelae \\
\hline 12 & 7.0 & $\mathrm{~F}$ & 28 & Iliofemoral deep venous thrombosis & & Survived, no sequelae \\
\hline 13 & 7.0 & M & 21 & $\begin{array}{l}\text { Inferior vena cava thrombosis, pulmonary } \\
\text { embolism }\end{array}$ & GABHS necrotizing fasciitis & Survived, small clot persists \\
\hline 14 & 11.0 & M & 30 & Iliofemoral deep venous thrombosis & & Postphlebitic syndrome \\
\hline
\end{tabular}

* Number of days from first VZV chicken pox identification to laboratory evaluation.

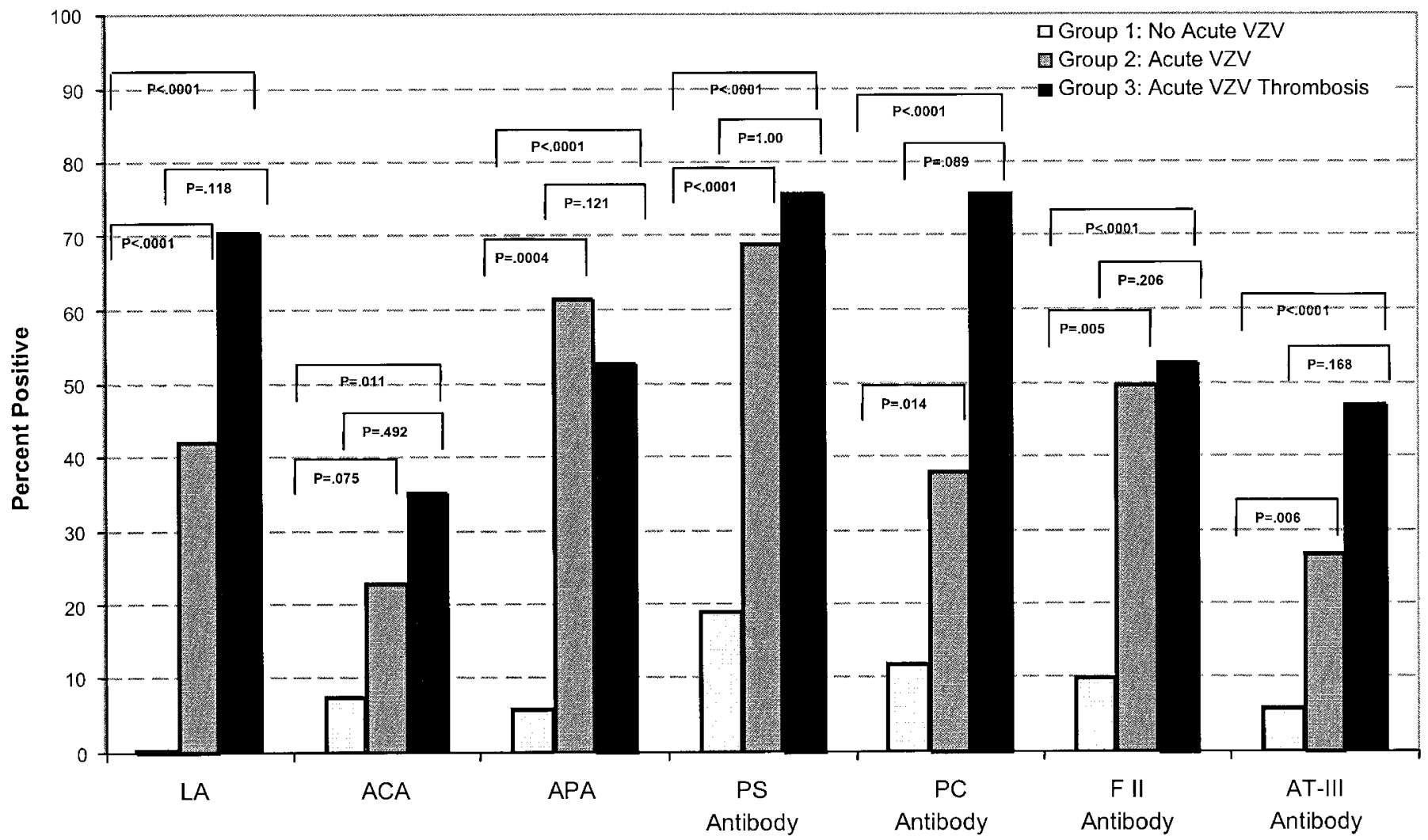

Figure 1. Prevalence of antiphospholipid and coagulation protein autoantibodies by group. Comparison of percent positive for each antiphospholipid and coagulation protein antibody assay among the three groups.

determined. Concentrations of purified antigens included PS, $2.5 \mu \mathrm{g} / \mathrm{mL}$; PC, $1.0 \mu \mathrm{g} / \mathrm{mL}$; F II, $1.2 \mu \mathrm{g} / \mathrm{mL}$; or AT, 0.15 $\mu \mathrm{g} / \mathrm{mL}$.

Because the ELISA assays use diluted patient plasma, it is possible that antibody reactions detected were against complexes of coagulation proteins with phospholipids. To control for this possibility, IgG antibodies were isolated using barium chloride precipitation and absorption with protein A Sepharose. Antibodies with specificity to varicella or VZV antigens were further purified by affinity chromatography using a commercial medium (3M Emphaze Biosupport medium, Pierce Chemical Co) that immobilized purified PS or VZV antigens.

\section{Statistical Methods}

ANOVA was used to test for differences in means among all three groups. When ANOVA showed statistically significant results, a $t$ test was used to compare means between two groups 
Table 2. Contingency coefficients (and $\mathrm{p}$ values) of positivity for autoantibodies to PS, PC, F II, or AT-III to positivity for LA, ACA, and $A P A$

\begin{tabular}{cccc}
\hline Coagulation antibody & LA & ACA & APA \\
\hline PS antibody & $0.476(<0.0001)$ & $0.319(0.0010)$ & $0.416(<0.0001)$ \\
PC antibody & $0.467(<0.0001)$ & $0.278(0.0049)$ & $0.326(0.0037)$ \\
F II antibody & $0.404(<0.0001)$ & $0.291(0.0031)$ & $0.265(0.0206)$ \\
AT-III antibody & $0.426(<0.0001)$ & $0.341(0.0005)$ & $0.358(0.0016)$ \\
\hline
\end{tabular}

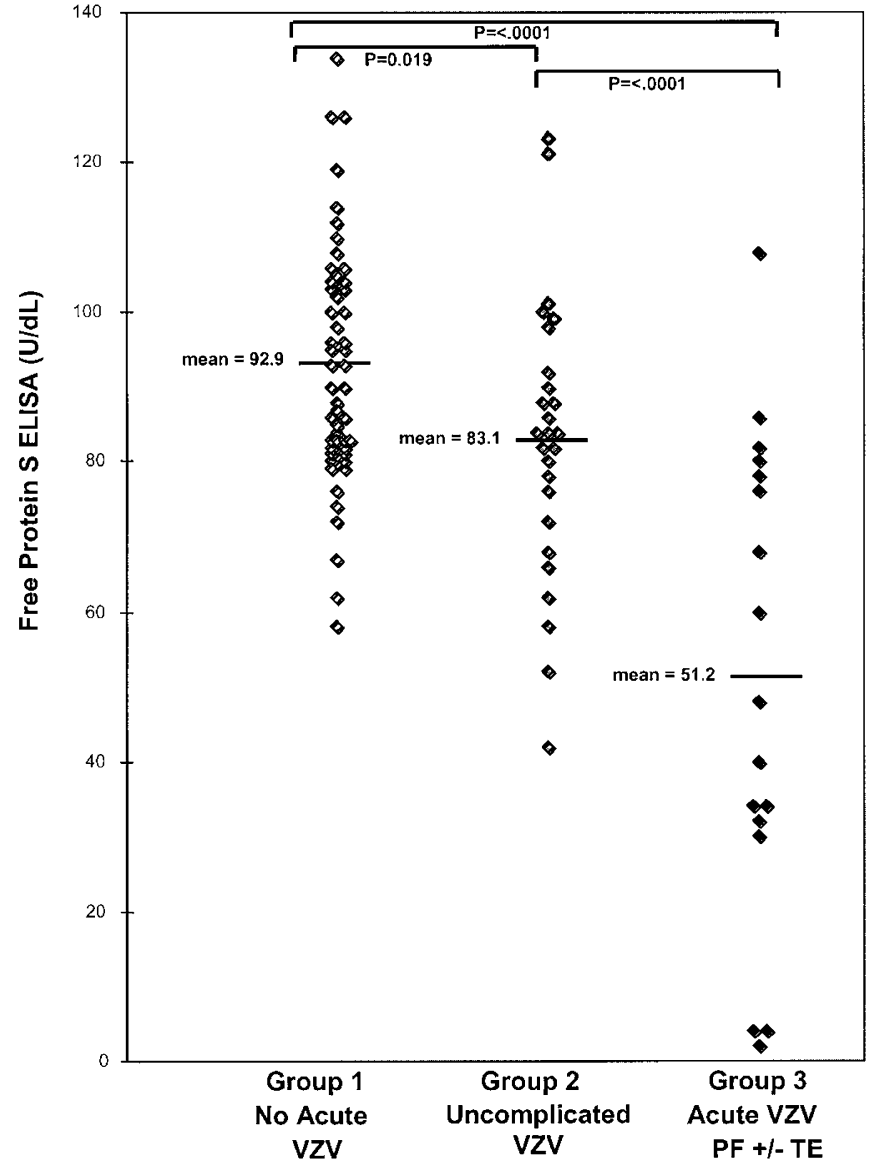

Figure 2. Distribution of free PS concentrations by group. Histograms show the mean and individual values for free PS concentrations in the study children.

at a time. This is not the most conservative approach, because it does not preserve the 0.05 level of significance. However, we chose this method to detect any real difference between two groups.

Fisher's exact test was used to test for differences in proportions among all three groups, because several of the comparisons had expected cell sizes that were fewer than five. When the Fisher's exact test showed statistically significant results, Fisher's exact test was also used to compare proportions between pairs of groups.

Contingency coefficients were calculated to determine relationships between dichotomous variables that were not normally distributed. The associated $p$ value for the $\chi^{2}$ was used to test statistical significance of the coefficients. Regression analysis was used to estimate the relationship between a dependent and an independent variable.

\section{RESULTS}

\section{Clinical Results}

Blood samples drawn from 95 children were studied. The samples were collected from March 1992 through October 1997. This study population includes the previously reported children with acute varicella infection (6).

Fifty-two children without acute VZV (group 1) had a mean age of 8.0 y (range, $3 \mathrm{wk}-17 \mathrm{y}$ ). Eighteen of these children were seronegative for VZV antibodies, and 34 children were seropositive with a history of clinical varicella $\geq 1$ y before sample collection. Sixty-three percent were female; $63 \%$ were white, $12 \%$ were Hispanic, $23 \%$ were African-American, and race/ethnicity was unknown for $2 \%$.

Twenty-six children had serologically confirmed acute uncomplicated VZV infection (group 2); they had a mean age of 5.5 y (range, $1-11$ y). Fifty-four percent were female; 58\% were white, $19 \%$ were Hispanic, and $23 \%$ were AfricanAmerican. Blood sample collection was performed a mean of $14.2 \mathrm{~d}$ after first chicken pox identification.

Seventeen children had serologically confirmed acute VZV complicated by $\mathrm{PF} \pm \mathrm{TE}$ (group 3). This group had a mean age of 5.5 y (range, 5 mo -14 y). Fifty-three percent were female; $71 \%$ were white, $12 \%$ were Hispanic, $6 \%$ were AfricanAmerican, and $12 \%$ were Asian. Blood sample collection was performed a mean of $17.6 \mathrm{~d}$ after first chicken pox identification. Table 1 lists the clinical presentation and outcome of group 3 subjects. Eight children were coinfected with Streptococcus; six had purpura fulminans. An additional child had purpura fulminans, but was coinfected with Pseudomonas.

\section{Laboratory Results}

Control experiments regarding antibody specificity. Isolated IgG antibodies reacted in the ELISA assay similar to diluted plasma, excluding the possibility that these antibodies are against complexes of proteins with phospholipid. IgG further isolated by affinity to VZV did not show positivity to PC, AT, or phospholipids in ELISA assays but did show positivity with PS and F II. This suggests that there may be cross-reactivity between VZV antigens and autoantibodies to PS and F II, but not between VZV and other coagulation proteins or phospholipids.

Laboratory results in children. The proportions of children who showed evidence for autoantibodies including APA or specific coagulation protein antibodies are displayed in Figure 1. All autoantibodies were significantly more prevalent in groups 2 and 3 as compared with group 1, with the exception of ACA in group 2 compared with group 1 . The prevalence of 


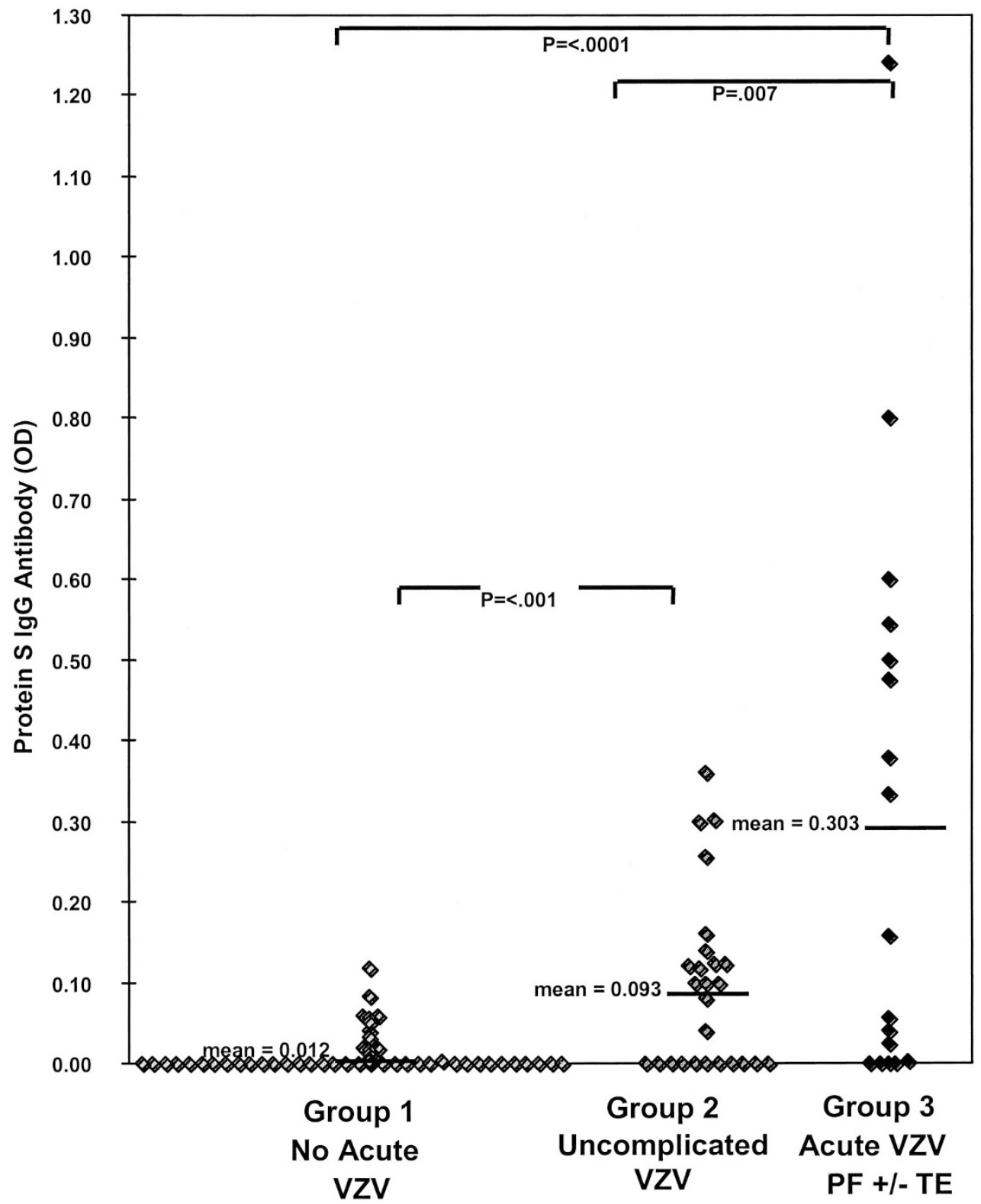

Figure 3. Distribution of PS IgG antibody concentrations by group. Histograms show the mean and individual values for PS IgG antibody concentrations in the study children.

autoantibodies was not significantly different in group 3 relative to group 2.

Seventy-five percent of the children in groups 2 and 3 who were positive for either APA or coagulation protein antibodies were positive for both. When examined by group, $88 \%$ of group 3 children with one autoantibody type were positive for both whereas $46 \%$ of group 2 children with one autoantibody type were positive for both. Those proportions were significantly different $(p=0.014)$. Results shown in Table 2 demonstrate highly significant correlations between autoantibodies.

The plasma concentration of free PS (Fig. 2) was significantly lower in group 3 compared with groups 1 or 2 and in group 2 versus group 1. PS IgG antibody levels (Fig. 3) were significantly elevated in group 3 compared with groups 1 and 2 , and group 2 levels were significantly higher than those in group 1. Pooling results of all samples, there was a negative correlation between PS IgG antibody levels and free PS concentration (Fig. 4, $r=-0.677 ; p<0.0001$ ). There were no significant correlations between IgG antibody binding and corresponding concentrations of PC, F II, and AT.

To estimate hypercoagulability, plasma concentrations of the $\mathrm{F} 1+2$ were determined (Fig. 5). The results show elevations in group 3 children $(p<0.0001)$ compared with groups 1 and 2. Groups 1 and 2 were not significantly different. We hypothesized that hypercoagulability was related to PS autoantibodies. In addition, a positive correlation was found between PS IgG antibody levels and concentrations of $\mathrm{F} 1+2$ (Fig. 6, $r=0.579 ; p<0.0001$ ).

Results in group 3 children were compared relative to diagnosis of purpura fulminans (Table 3). Group 3 children with PF did not differ from those without PF with respect to the following: age; activated partial thromboplastin time; 


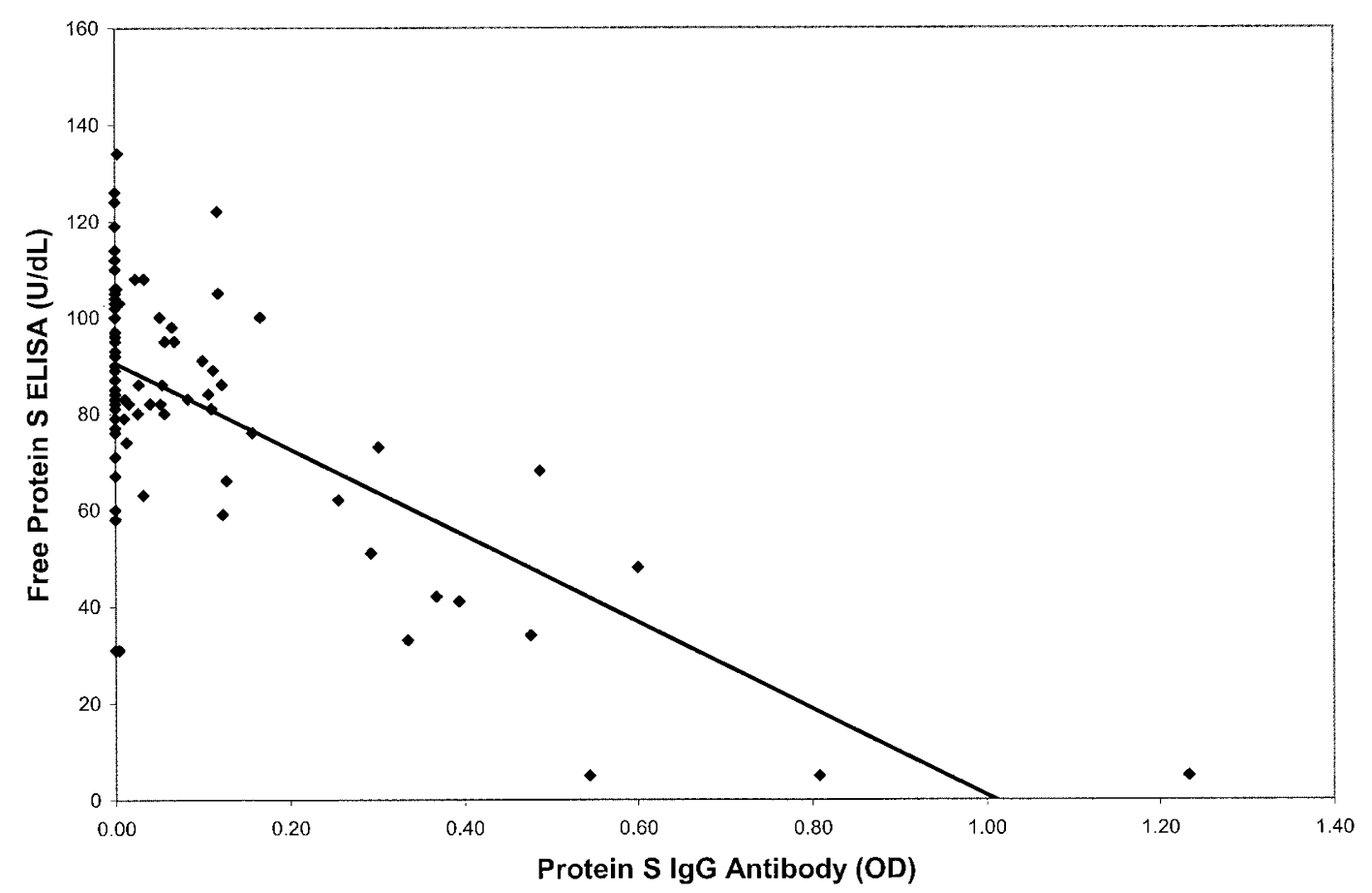

Figure 4. Correlation of free PS concentrations to PS IgG antibody levels. Regression plot compares the concentration of free PS in all groups to the titer of the corresponding PS IgG antibody $(p<0.0001)$.

dilute Russell viper venom time; concentrations of free PS, PC, F II, or F 1+2; or ELISA bindings to PS, PC, AT, or F II (all $p>0.30$ ). The mean time to diagnosis of PF was $6.7 \mathrm{~d}$ after onset of VZV compared with $23.4 \mathrm{~d}$ to diagnosis of thromboembolism $(p<0.001)$ after onset of VZV. In addition, AT activity was lower in children with PF $(0.66$ $\mathrm{U} / \mathrm{mL})$ than in children with thromboembolism alone (1.13 $\mathrm{U} / \mathrm{mL}, p=0.005$ ).

Eight children in group 3 had clinical evidence of bacterial sepsis or superinfection of the varicella lesions. All eight clinically suspected infections were proven by culture to be GABHS. The mean levels of PS IgG antibody and F $1+2$ in these eight children were not statistically different from the other nine children in group $3(p>0.05)$. However, the mean PS concentration in the GABHS-infected children was significantly lower than the mean for the other group 3 children $(p=$ 0.036).

The three group 1 children who developed VZV infection after their initial samples were drawn underwent blood sampling during the acute and convalescent phases of infection as well. The mean pre-VZV values for these three children are as follows: PS, 98.0 U/dL; PS IgG, 0.023 OD; PC, 93.5 U/dL; PC IgG, 0.013 OD; F II, 96.5 U/dL; F II IgG, 0.00 OD; F 1+2, $0.837 \mathrm{nM}$. An additional seven children from groups 2 and 3 had samples drawn during and $\geq 3$ mo after acute VZV infection. Table 4 includes mean values for the acute and convalescent phases of these 10 children. Comparisons of acute and convalescent mean values in these 10 children show that elevations in $\operatorname{IgG}$ binding to PS and $\mathrm{F} 1+2$, as well as a decrease in concentration of free PS, are transient. Nine of the children had a transient LA. Results also demonstrated normal baseline values, mild changes at the time of acute VZV infection, and return toward baseline values by 3 mo after infection.

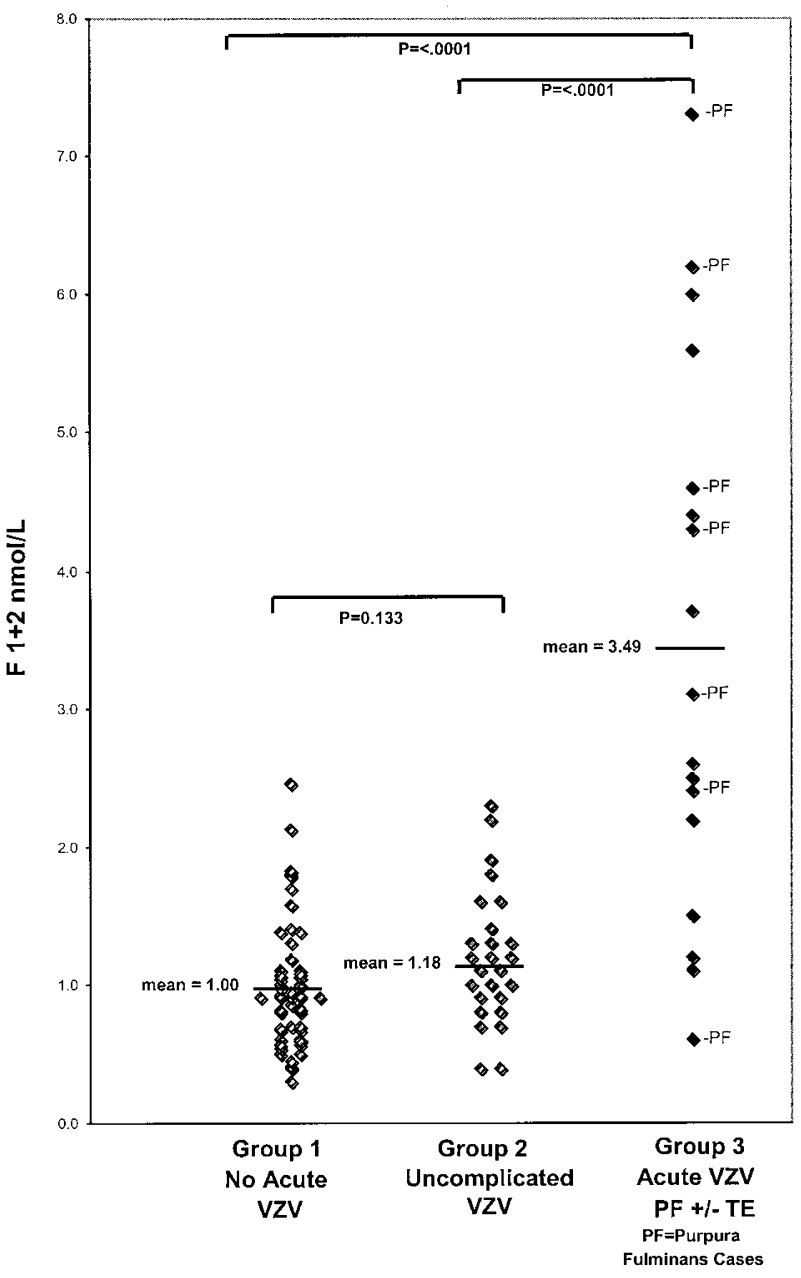

Figure 5. Distribution of $\mathrm{F} 1+2$ concentrations by group. Histograms show the mean and individual values for $\mathrm{F} 1+2$ concentrations in the study children. 


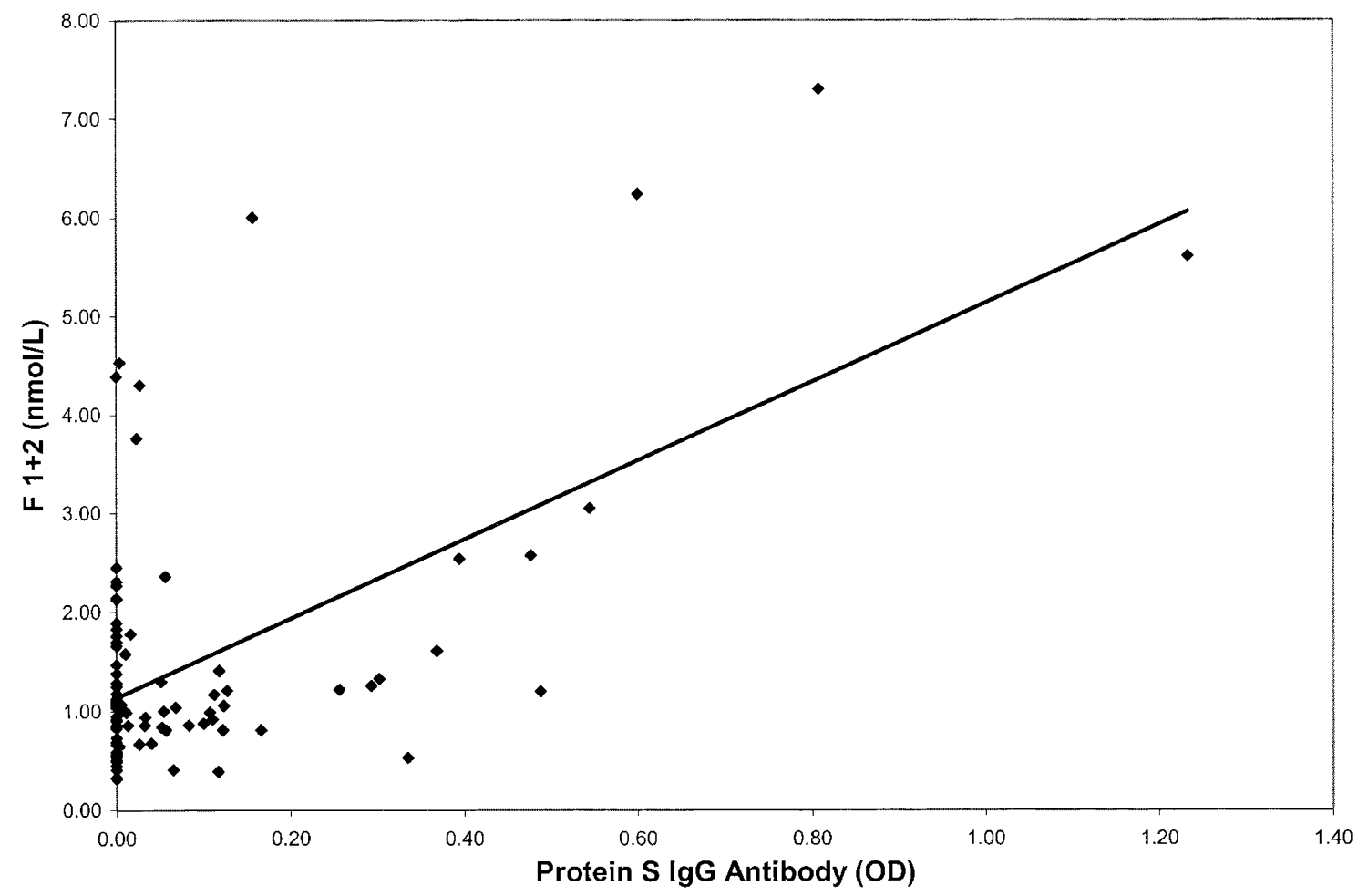

Figure 6. Correlation of F $1+2$ concentrations to PS IgG antibody levels. Regression plot compares the concentration of F $1+2$ to the titer of the corresponding PS IgG antibody levels, $(p<0.0001)$.

Table 3. Comparison of group 3 children relative to diagnosis of $P F$

\begin{tabular}{lccc}
\hline \multicolumn{1}{c}{ Result } & PF present & PF absent & $p$ value \\
\hline $\mathrm{N}$ & 7 & 10 & \\
Age (y) & 3.0 (SD 4) & 3.9 (SD 4.8) & 0.39 \\
Time to onset after VZV (d) & 6.7 (SD 4.3) & 23.4 (SD 11.1) & 0.001 \\
Females (\%) & 71 & 40 & 53 (SD 28) \\
PTT (s) & 75.6 (SD 60) & 45.5 (SD 16) & 0.38 \\
DRVVT (s) & 51.1 (SD 12) & 0.53 (SD 0.36) & 0.45 \\
Free PS (U/mL) & 0.47 (SD 0.29) & 0.74 (SD 0.23) & 0.72 \\
PC (U/mL) & 0.52 (SD 0.28) & 1.13 (SD 0.28) & 0.13 \\
AT-II activity (U/mL) & 0.66 (SD 0.23) & 0.73 (SD 0.32) \\
F II activity (U/mL) & 0.57 (SD 0.28) & 3.14 (SD 2.3) \\
F 1 + 2 (nM) & 3.97 (SD 1.5) & 0.34 \\
\hline
\end{tabular}

Abbreviations: PTT, prothrombin time; DRVVT, dilute Russell viper venom time.

Table 4. Results of 10 children during acute VZV and convalescent

\begin{tabular}{|c|c|c|c|}
\hline \multicolumn{4}{|c|}{ phase } \\
\hline Variable & $\begin{array}{c}\text { Mean acute } \\
\text { value } \\
(\mathrm{n}=10)\end{array}$ & $\begin{array}{c}\text { Mean } \\
\text { convalescent } \\
\text { value } \\
(\mathrm{n}=10)\end{array}$ & $p$ value \\
\hline PS concentration (U/dL) & 51.6 & 87.3 & 0.010 \\
\hline PS IgG antibody (OD) & .391 & .147 & 0.015 \\
\hline $\mathrm{PC}$ concentration $(\mathrm{U} / \mathrm{dL})$ & 65.4 & 69.6 & 0.602 \\
\hline PC IgG antibody (OD) & .109 & .051 & 0.183 \\
\hline F II concentration $(\mathrm{U} / \mathrm{dL})$ & 76.6 & 98.5 & 0.130 \\
\hline F II IgG antibody (OD) & .187 & .111 & 0.349 \\
\hline $\mathrm{F} 1+2(\mathrm{nM})$ & 2.78 & .942 & 0.035 \\
\hline
\end{tabular}

\section{DISCUSSION}

VZV is an early childhood viral infection that elicits a brisk immunologic response. Because of its unusually long incubation period (14-21 d), infected children are generally found to have IgG antibodies at the time of or shortly after presentation with skin lesions. IgG-mediated postinfectious autoimmune disorders, including immune thrombocytopenia purpura, can present in VZV-infected children (11). We previously reported that some children with VZV infection complicated by PF \pm TE had evidence of APA (6). In addition, these children had PS antibodies. The PS antibodies were nonneutralizing and appeared to increase PS clearance from plasma. We speculated that these PS antibodies correlated with the thrombotic potential $(2,6)$.

In this study of previously healthy children with VZV infection we found a significantly higher prevalence of APA and coagulation protein autoantibodies compared with children without acute $\mathrm{VZV}$. In general, the presence of APA and coagulation protein antibodies was similar among all children with acute varicella, regardless of whether they had complications. Other studies have shown that the LA is more prevalent in children after infection $(12,13)$. Although controversial, there are data relating postinfectious LAs to thrombosis (14-18). 
In evaluating the groups to detect a marker that correlated with thrombosis, we found that children with VZV complicated by $\mathrm{PF} \pm \mathrm{TE}$ had significantly higher mean PS IgG antibody levels, significantly decreased mean PS levels, and significantly elevated mean F $1+2$ concentrations as compared with control children and those with uncomplicated varicella. These findings were independent of the diagnosis of PF. The pattern of immunologic response was the same in children with VZV infection with or without thrombotic complications, but the intensity of the antibody response was greater in children with $\mathrm{PF} \pm \mathrm{TE}$.

Similar to VZV, infection with Streptococcus has previously been shown to induce a number of autoimmune diseases, including immune thrombocytopenia purpura, acute rheumatic fever, and Sydenham's chorea $(19,20)$. VZV appears to increase susceptibility of children to streptococcal infection (21). Both VZV and GABHS infect skin and endothelial cells. The physical trauma of this coinfection may have triggered thrombus initiation. Although our study was not designed to test the effect of GABHS on the immune system or clinical course in children with VZV, the observed high coinfection rate in group 3 remains interesting.

There are several possible explanations for the observed results. VZV may allow the presentation of the host antigens in a manner that causes an autoimmune response. This has been observed in a mouse model of autoimmune myocarditis after coxsackie infection $(22,23)$. In that model, autoantibodies to cardiac myosin were related to presentation of cardiac myosin to $T$ cells with very high expression of cytokines IL-1 and tumor necrosis factor. Alternatively, there could be epitope mimicry between the infecting virus and a host protein(s) causing an autoimmune response by cross-reactivity. This mechanism has also been described in a mouse model of viral myocarditis $(24,25)$. Finally, VZV may stimulate a very robust but nonspecific immunologic response that includes antibodies against phospholipids and a spectrum of coagulation proteins.

We conclude that acute VZV infection predisposes children to a brisk but nonspecific immunologic response with multiple antiphospholipid and coagulation autoantibodies. A small number of children with autoantibodies associated with VZV have $\mathrm{PF} \pm \mathrm{TE}$. These children appear to have a more specific autoimmune effect on PS, supporting the possibility that epitope mimicry, if involved, may be limited to VZV and PS cross-reactivity. In addition, GABHS may act as a trigger or cofactor in thrombus initiation. Further study of the molecular and immunologic mechanisms of the varicella-autoantibody syndrome is clearly warranted.

\section{REFERENCES}

1. Francis RB 1990 Acquired purpura fulminans. Semin Thromb Hemost 16:310-325

2. Manco-Johnson MJ, Lefkowitz J, Nuss R, Hays T 1992 Purpura fulminans (PF) in a child with varicella, a lupus anticoagulant (LA) and severe protein S (PS) deficiency. Blood 80:510a(abstr)

3. D'Angelo A, Della Valle P, Crippa L, Pattarini E, Grimaldi LME, D'Angelo SV 1993 Brief report: autoimmune protein $\mathrm{S}$ deficiency in a boy with severe thrombotic disease. N Engl J Med 328:1753-1757

4. Nguyen P, Reynaud J, Pouzol P, Munzer M, Ricard O, Francois P 1994 Varicella and thrombotic complications associated with transient protein $\mathrm{C}$ and protein $\mathrm{S}$ deficiencies in children. Eur J Pediatr 153:646-649

5. Levin M, Eley B, Louis J, Cohen H, Young L, Heyderman R 1995 Postinfectious purpura fulminans caused by an autoantibody directed against protein S. J Pediatr 127:355-363

6. Manco-Johnson MJ, Nuss R, Key N, Moertel C, Jacobson L, Meech S, Weinberg A, Lefkowitz J 1996 Lupus anticoagulant and protein S deficiency in children with postvaricella purpura fulminans or thrombosis. J Pediatr 128:319-323

7. Peyton BD, Cutler BS, Stewart FM 1998 Spontaneous tibial artery thrombosis associated with varicella pneumonia and free protein S deficiency. J Vasc Surg 27:563-567

8. Woods C, Johnson C 1998 Varicella purpura fulminans associated with heterozygosity for factor V Leiden and transient protein S deficiency. Pediatrics 102:1208-1210

9. Brandt JT, Triplett DA, Alving B, Scharrer I 1995 Criteria for the diagnosis of lupus anticoagulants: an update. On behalf of the Subcommittee on Lupus Anticoagulant/ Antiphospholipid Antibody of the Scientific and Standardization Committee of the ISTH. Thromb Haemost 74:1185-1190

10. Hughes GRV, Harris EN, Gharavi AE 1986 The anticardiolipin syndrome. J Rheumatol 133:486-489

11. Rudolph AM, Hoffman JIE, Rudolph CD 1996 Rudolph's Pediatrics, 20th Ed. Appleton and Lange, Stamford, p 241

12. Shi W, Krilis SA, Chong BH, Gordon S, Chesterman CN 1990 Prevalence of lupus anticoagulant or anticardiolipin antibodies in a healthy population. Aust NZ J Med 20:231-236

13. Burk C, Miller L, Handler S, Cohen A 1992 Preoperative history and coagulation screening in children undergoing tonsillectomy. Pediatrics 89:691-695

14. Manco-Johnson M 1998 Antiphospholipid antibodies in children. Semin Thromb Hemost 24:591-598

15. Manco-Johnson M, Nuss R 1995 Lupus anticoagulant in children with thrombosis. Am J Hematol 48:240-243

16. Singh AK, Rao KP, Kizer J, Lazarchick J 1988 Lupus anticoagulants in children. Ann Clin Lab Sci 18:384-387

17. Muntean W, Petek W 1980 Lupus anticoagulant after measles. Eur J Pediatr 134:135138

18. Corrigan JJ, Patterson JH, May NE 1970 Incoagulability of the blood in systemic lupus erythematosus: a case due to hypoprothrombinemia and a circulating anticoagulant. Am J Dis Child 119:365-369

19. Stollerman GH 1991 Rheumatogenic streptococci and autoimmunity. Clin Immunol Immunopathol 61:131-142

20. Sibofsky A, Kerwar S, Zabriskie JB 1998 Rheumatic fever: the relationships between host, microbe and genetics. Rheum Dis Clin North Am 24:237-259

21. Peterson CL, Mascola L, Chao SM, Lieberman JM, Arcinue EL, Blumberg DA, Kim KS, Kovacs A, Wong VK, Brunell PA 1996 Children hospitalized for varicella: a prevaccine review. J Pediatr 129:529-536

22. Neumann DA, Rose NR, Ansari AA, Herskowitz A 1994 Induction of multiple heart autoantibodies in mice with coxsackie B3-and cardiac myosin-induced autoimmune myocarditis. J Immunol 152:343-350

23. Rose NR, Hill SL 1996 Autoimmune myocarditis. Int J Cardiol 54:171-175

24. Gauntt CJ, Arizpe JM, Higdon AL Wood HJ, Bowers DF, Rozek MM, Crawley R 1995 Molecular mimicry: anti-coxsackie B3 neutralizing monoclonal antibodies and myocarditis. J Immunol 154:2983-2995

25. Beisel KW, Scrinivasappa J, Prabhakar BS 1991 Identification of a putative shared epitope between coxsackie virus B4 and alpha cardiac myosin heavy chain. Clin Exp Immunol 86:49-55 